\title{
The impact of C-reactive protein levels on headache frequency in the HUNT study 2006-2008
}

\author{
Knut Hagen ${ }^{1,2,3^{*}} \mathbb{D}$, Lars Jacob Stovner ${ }^{1,2}$, Kristian Bernhard Nilsen ${ }^{4}$, Espen Saxhaug Kristoffersen ${ }^{5,6}$ and \\ Bendik Slagsvold Winsvold 7,8
}

\begin{abstract}
Background: Increased high sensitivity C- reactive protein (hs-CRP) levels have been found in many earlier studies on migraine, and recently also in persons with migraine and insomnia. The aim of this study was to see whether these findings could be reproduced in a large-scale population-based study.

Methods: A total of 50,807 (54\%) out of 94,194 invited aged $\geq 20$ years or older participated in the third wave of the Nord-Trøndelag Health Study study performed in 2006-2008. Among these, 38,807 (41\%) had valid measures of hs-CRP and answered questions on headache and insomnia. Elevated hs-CRP was defined as $>3.0 \mathrm{mg} / \mathrm{L}$. The crosssectional association with headache was estimated by multivariate analyses using multiple logistic regression. The precision of the odds ratio (OR) was assessed with 95\% confidence interval (Cl).

Results: In the fully adjusted model, elevated hs-CRP was associated with migraine (OR 1.14, 95\% Cl 1.04-1.25) and migraine with aura (OR 1.15,95\% Cl 1.03-1.29). The association was strongest among individuals with headache $\geq 15$ days/month for any headache (OR 1.26, 95\% Cl 1.08-1.48), migraine (OR 1.62, 95\% Cl 1.21-2.17), and migraine with aura (OR 1.84, 95\% Cl 1.27-2.67). No clear relationship was found between elevated hs-CRP and headache less than 7 days/month or with insomnia.
\end{abstract}

Conclusions: Cross-sectional data from this large-scale population-based study showed that elevated hs-CRP was associated with headache $\geq 7$ days/month, especially evident for migraine with aura.

\section{Background}

During the last decade many studies have evaluated the association between migraine and high sensitivity $\mathrm{C}$ reactive protein (hs-CRP) [1-25]. Several case-control studies $[3,7,8,14,18-22]$ and some population-based studies $[4,6]$ have found higher CRP values in migraine patients, but negative results have been reported by others $[2,5,6,10,11,15,16,24]$. A summary of recently published studies concluded that migraineurs had higher CRP levels than controls [26].

The association between headache and insomnia is well-established [27], but the impact of insomnia on the

\footnotetext{
* Correspondence: knut.hagen@ntnu.no

1 Department of Neuromedicine and Movement science, NTNU Norwegian

University of Science and Technology, 7491 Trondheim, Norway

${ }^{2}$ Norwegian Advisory Unit on Headache, St. Olavs Hospital, Trondheim,

Norway

Full list of author information is available at the end of the article
}

relationship between hs-CRP and migraine is unclear. Previously, a prospective study has demonstrated higher level of CRP in individuals with shorter sleep duration [28]. In a recent population-based cross-sectional study from Northern Norway, elevated hs-CRP was associated with migraine, but only among those with co-existing insomnia [29]. However, since the results on hs-CRP and migraine are conflicting, and the relationship to insomnia only reported in one study, it is important to replicate the analyses in other population-based study with similar design.

The aim of this large-scale population-based study was to evaluate the cross-sectional association between hsCRP and types of headache, and to see whether the relationship to insomnia could be reproduced.

(c) The Author(s). 2019 Open Access This article is distributed under the terms of the Creative Commons Attribution 4.0 International License (http://creativecommons.org/licenses/by/4.0/), which permits unrestricted use, distribution, and reproduction in any medium, provided you give appropriate credit to the original author(s) and the source, provide a link to the Creative Commons license, and indicate if changes were made. The Creative Commons Public Domain Dedication waiver (http://creativecommons.org/publicdomain/zero/1.0/) applies to the data made available in this article, unless otherwise stated. 


\section{Methods}

\section{Study design}

The present population-based study of a large unselected adult population replicate the methodological design used in the Tromsø Study [29], including similar questionnaire-based diagnoses for headache and insomnia, identical categories of hs-CRP, and replication of the statistical analyses with adjustments for the same type of potential confounders.

\section{The Nord-Trøndelag health study}

The total population of the Nord-Trøndelag county aged $\geq 20$ years has been invited four times between 1984 and 2019. All participant answered questionnaires and were invited to interview, clinical examination, and blood sampling [30].

\section{Study population}

In HUNT3 (2006-2008), a total of 94,194 individuals aged $\geq 20$ years were invited, whereof 93,860 were eligible. Of these, 50,807 (54\%) accepted the invitation. The diagnoses of headache and insomnia was questionnaire-based. The present study included data from 38,813 participants (41\%) (mean age 54.1 years, range 20-97 years) who had answered questions about headache and insomnia and had hs-CRP measured from non-fasting blood samples (Fig. 1).

\section{C-reactive protein}

Hs-CRP was analyzed at the Central Laboratory, Levanger Hospital, using Architect cSystem ci8200, by latex immunoassay method. The detection limit was $0.03 \mathrm{mg} /$ $\mathrm{L}$, and samples without detectable hs-CRP were assigned this value. In the present study we replicated the strategy used in previous published studies from the Troms $\varnothing$ study $[29,31]$ defining normal hs-CRP as $0-3.00 \mathrm{mg} / \mathrm{L}$ and elevated as $3.01-20.00 \mathrm{mg} / \mathrm{L}$. Participants with hsCRP values $>20.00 \mathrm{mg} / \mathrm{L}$, which probably indicate some acute or chronic disease [32], were excluded $(n=527)$ (Fig.1). Blood samples for hs-CRP analyzes were drawn without any knowledge about last headache attack.

\section{Headache questionnaire}

All details of the headache questionnaire have been published elsewhere [33], and all questionnaire-based headache diagnoses were identical to those presented in the Tromsø study [29]. Subjects who answered "no" to the screening question ("Have you suffered from headache during the last 12 months?") were included in the reference group without headache.

Participants who answered "yes" completed 12 additional questions, mainly to diagnose migraine according to the second version of the International Classification of Headache Disorders (ICHD-2) [34]. Regarding attack duration, $<4 \mathrm{~h}$ were accepted for those who reported visual disturbance before headache. Participants who fulfilled the migraine diagnosis and reported visual

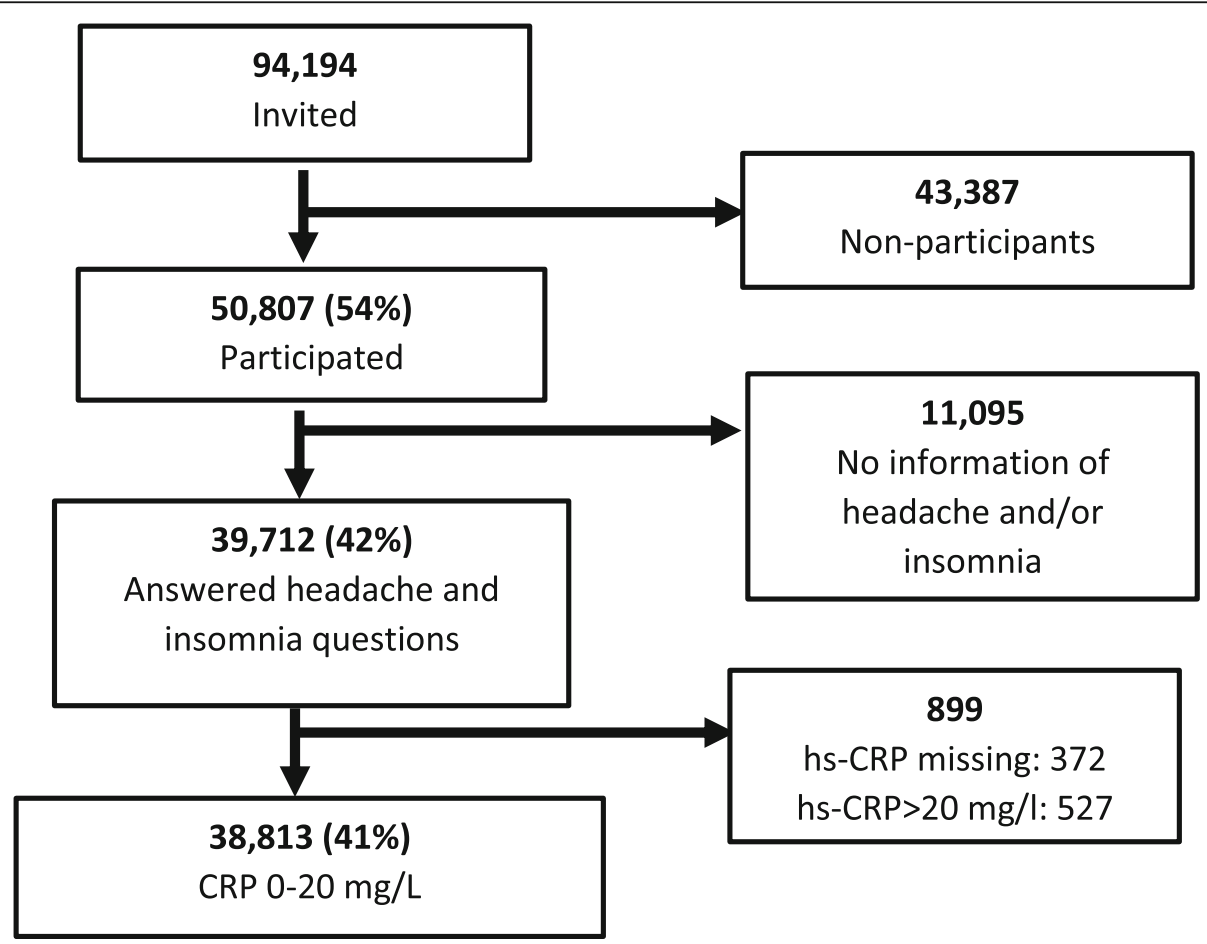

Fig. 1 Flowchart of participation in the HUNT Study 2006-2008. Hs-CRP = high sensitivity C-reactive protein 
disturbance prior to headache were classified as migraine with aura (MA), whereas the remaining with migraine had migraine without aura (MO). The remaining participants with headache were classified as having "other headache". The merged group of "any headache" consisted of participants with migraine or other headache. Furthermore, based to answer on the question about headache frequency, subjects were subdivided into five groups; no headache, headache $<1$ days/month, headache 1-6 days/month, headache 7-14 days/month, or headache $\geq 15$ days/month.

The validity of the questionnaire-based headache diagnoses has been published in a separate paper [39]. The agreement between the validation interview and questionnaire-based headache categories were very good for any headache (kappa value at $0.70,95 \%$ CI $0.61-$ 0.79 ) and moderate for migraine (kappa value $0.50,95 \%$ CI 0.32-0.68), whereas the specificity for MA was high (95\%) (kappa value 0.44, 95\% CI 0.38-0.50) (33).

\section{Questionnaire-based diagnosis of insomnia}

The questionnaire-based diagnosis of insomnia was based on the DSM-V (Diagnostic and Statistical Manual of Mental Disorders, 5th ed.), and was nearly identical to the insomnia diagnosis used in the Tromsø study [29]. To fulfil the proxy diagnosis of insomnia the participants had to answer "several times a week" to at least one out of the three questions, asking whether they had "difficulties falling asleep at night", whether they "woke up repeatedly during the night", and/or whether they "woke up too early and could not get back to sleep" [36]. In addition, they also had to report "several times a week" to the question "felt sleepy during day" [36]. The overall agreement between questionnaire and interview for the first three questions has previously been found to be moderate (kappa value $0.51,95 \%$ CI $0.40-0.63$ ) [37].

\section{Potential confounders}

The selection of potential confounders used in the Troms $\emptyset$ study [29] was based on previous literature [35, 37]. To replicate the Tromsø study [29], we included almost identical potential confounders, with two exceptions: employment status was used instead of education level, and Hospital Anxiety and Depression Scale instead of Hopkins symptom checklist (HSCL-10). The remaining potential confounders were identical; age (continuous variable); gender; body mass index (BMI) $(<$ $25, \quad 25.0-29.9$, and $\left.\geq 30 \mathrm{~kg} / \mathrm{m}^{2}\right) \quad(28, \quad 32)$; smoking (current, previous, and never); physical activity (never, $\leq$ 1 time per week, $\geq 2$ times per week); alcohol consumption (never, $<2$ times/week, $\geq 2$ times/week); selfreported diabetes (yes/no); self-reported stroke and/or heart infarction (yes/no); and self-reported hypertension (yes/no).

\section{Ethics}

This study was approved by the Regional Committee for Medical and Health Research Ethics, the Faculty of medicine, mailbox 8905, 7491 Trondheim. The approval number was \#2018/2422/Rek Midt. The participants have given written informed consent.

\section{Statistical analysis}

The statistical method was identical to that presented in the Tromsø Study [29] and based on multivariate analyses using multiple logistic regression. The precision of the odds ratio (OR) was assessed with 95\% confidence interval $(\mathrm{CI})$. We present results for three different statistical models separated by number of confounders included; model 1 (age and sex), model 2 (age, sex and BMI), and model 3 (all other factors were tested). In model 3 we excluded factors if they did not change OR when evaluating each factor separately or when including several factors grouped together (i.e. self-reported diabetes, stroke/heart infarction, and hypertension). Potential interaction between two variables was evaluated by including the product of the variable in the logistic regression analyses, and the interaction was tested using Wald $x^{2}$ statistics. To evaluate the probability of a linear relationship between elevated hs-CRP and headache frequency, the five categories were treated as a single variable and was incorporated in a two-sided test for trend. Subjects with missing data of confounding factors (numbers reported in Table 1) were included in the analysis to reduce the impact of possible bias.

To evaluate insomnia as a modifying factor on the association between hs-CRP and types of headache, we repeated the multi-adjusted analyses in model 3 in those with and without insomnia.

Analyses were performed with the IBM SPSS version 25 (SPSS, Chicago, Illinois, USA).

\section{Results}

Subjects with headache were more likely to be women, younger, and to be employed in paid work compared to those without headache (Table 1).

\section{Prevalence of headache}

A total of 13,990 (36.0\%) participants suffered from headache during the last year, 3793 (9.8\%) fulfilled the criteria of migraine, 2139 (5.5\%) had migraine with aura (MA), 1654 (4.3\%) migraine without aura (MO), and 10, 197 (26.3\%) had other headaches.

\section{The association between elevated hs-CRP and headache}

In the multivariate analyses, adjusting for age and sex, elevated hs-CRP was associated with any headache (OR 1.11, 95\% CI 1.05-1.17), migraine (OR 1.23, 95\% CI 
Table 1 Characteristics of participants $(n=38,813)$ in the HUNT3 study related to headache types

\begin{tabular}{|c|c|c|c|c|c|}
\hline & No headache & Any headache & MA & $\mathrm{MO}$ & Other headaches \\
\hline Participants, n & 24,823 & 13,990 & 2139 & 1654 & 10,197 \\
\hline Women, n (\%) & $12,525(50.5)$ & $9203(65.8)$ & $1600(74.8)$ & $1252(75.7)$ & $6351(62.2)$ \\
\hline Mean age, years (SD) & $56.9(15.7)$ & $49.2(14.2)$ & $47.0(12.9)$ & $45.3(12.6)$ & $50.2(14.6)$ \\
\hline Age $\geq 60$ years (\%) & $11,280(45.4)$ & $3264(23.3)$ & $358(16.7)$ & $219(13.2)$ & $2687(26.4)$ \\
\hline Employed, $\mathrm{n}(\%)($ missing $=17)$ & $14,450(58.2)$ & $10,087(72.1)$ & $1570(73.4)$ & $1301(78.7)$ & $7216(70.8)$ \\
\hline Current daily smoking, $\mathrm{n}(\%)($ missing $=998)$ & $3590(14.5)$ & $2534(18.1)$ & $497(23.2)$ & $277(16.7)$ & $1760(17.3)$ \\
\hline Mean $\mathrm{BMl}, \mathrm{kg} / \mathrm{m}^{2}(\mathrm{SD})$ (missing $=120$ ) & $27.2(4.2)$ & $27.2(4.7)$ & $27.3(4.8)$ & $27.1(5.0)$ & $27.2(4.6)$ \\
\hline Total HADS score (missing = 582) & $6.7(5.0)$ & $8.3(5.9)$ & $9.4(6.4)$ & $8.2(5.9)$ & $8.1(5.8)$ \\
\hline Alcohol abstainers during last year, $\mathrm{n}(\%)($ missing = 956) & $2215(8.9)$ & $1105(7.9)$ & $120(7.3)$ & $182(8.5)$ & $803(7.9)$ \\
\hline Physical inactivity, $\mathrm{n}(\%)$ (missing = 615) & $1231(5.0)$ & $574(4.1)$ & $69(3.2)$ & $63(3.8)$ & $442(4.3)$ \\
\hline Self-reported hypertension, n (\%) & $6503(26.2)$ & $2462(17.6)$ & $359(16.8)$ & $215(13.0)$ & $1888(18.5)$ \\
\hline Self-reported stroke and/or heart infarction (\%) & $1771(7.1)$ & $506(3.6)$ & $63(2.9)$ & $33(2.0)$ & $410(4.0)$ \\
\hline Self-reported diabetes mellitus, n (\%) & $1326(5.3)$ & $466(3.3)$ & $60(2.8)$ & $34(2.1)$ & $372(3.6)$ \\
\hline Modified DSM-V insomnia, n (\%) & $1057(4.3)$ & $1631(11.7)$ & $362(16.9)$ & $235(14.2)$ & $1034(10.1)$ \\
\hline Mean hs-CRP (95\% Cl) & $2.2(2.2-2.3)$ & $2.3(2.2-2.3)$ & $2.4(2.3-2.5)$ & $2.2(2.1-2.4)$ & $2.3(2.2-2.3)$ \\
\hline
\end{tabular}

MA Migraine with aura, MO Migraine without aura, HADS Hospital anxiety and depression scale, BMI Body mass index, hs-CRP High sensitivity C-reactive protein, $C l$ Confidence intervals, DSM-V Diagnostic and statistical manual of mental disorders, 5th ed.

1.13-1.34), MA (OR 1.26, 95\% CI 1.13-1.40), MO (OR 1.17, 95\% CI 1.03-1.32), and other headache (OR 1.08, 95\% CI 1.02-1.14). In the final model 3, adjusting for all potential confounding factors, elevated hs-CRP was still significantly associated with migraine (OR 1.14, 95\% CI 1.04-1.25) and MA (OR 1.25, 95\% CI 1.03-1.29) (Table 2). In supplementary analyses, using individuals with "other headache "as reference category, elevated hsCRP was more likely among those with MA (OR 1.17, 95\% CI 1.05-1.31), but not MO (OR 1.04, 95\% CI 0.921.19).

No interaction was observed. As to the impact of headache frequency, the strongest association with elevated hs-CRP was found among individuals with headache $\geq 15$ days/month for any headache (OR 1.26, 95\% CI 1.08-1.48), migraine (OR 1.62, 95\% CI 1.21-2.17), and MA (OR 1.84, 95\% CI 1.27-2.67) (Table 2). A significant linear trend between increasing headache frequency and elevated hs-CRP was found for any headache $(p=0.01)$, migraine $(p=0.01)$ and MA $(p=$ 0.002) (Table 2). No clear relationship was found between elevated hs-CRP and headache less than 7 days/month (Table 2).

\section{The influence of insomnia diagnosis}

As demonstrated by Table 3, the relationship between elevated hs-CRP and headache was only found among subjects without insomnia, whereas no such association was found among those with insomnia. Supplementary analyses considering only those with headache 7-14 days/month and $\geq 15$ days/month did not change the results (data not shown).

\section{Discussion}

Cross-sectional population-based data based on a large number of participants showed that elevated hs-CRP was associated with headache $\geq 7$ days/month, most evident for migraine with aura. No relationship was found between elevated hs-CRP and headache less than 7 days/ month or with insomnia.

In agreement with the present results, a previous study have demonstrated that women with migraine had elevated CRP compared to women without migraine [4]. In a Dutch case-control study, individuals with MA were more likely to have elevated hs-CRP in the unadjusted analyses, and a borderline tendency was found in the multi-adjusted model [24]. In contrast, in a populationbased study from Iceland, no difference in CRP levels were found between participants with and without migraine [6].

In the present study, the final multi-adjusted analyses showed that MA, but not MO, was associated with elevated hs-CRP. This is in contrast with a review of previous studies on this topic, where the association to MA was not found to be consistently stronger than to MO [26]. It should be highlighted that an association between hs-CRP and average number of aura attacks and total number of years with aura were reported in the Dutch study [24].

\section{Interpretation}

In accordance with findings in the Tromsø 7 Study [29], MA was most consistently associated with elevated hsCRP. It may be of relevance that hs-CRP is associated with risk of cardiovascular events [38], and that ischemic 
Table 2 Odds ratio (OR) with 95\% confidence interval (Cl) of high sensitivity C-reactive protein (hs-CRP) defined as > 3.0-20.0 mg/l related to headache types

\begin{tabular}{|c|c|c|c|c|c|}
\hline \multirow{2}{*}{\multicolumn{2}{|c|}{ Total }} & High hs-CRP & Model 1 & Model 2 & Model 3 \\
\hline & & N & OR (95\% Cl) & OR $(95 \% \mathrm{Cl})$ & OR $(95 \% \mathrm{Cl})$ \\
\hline No headache & 24,823 & 5179 & 1.00 & 1.00 & 1.00 \\
\hline Any headache & 13,990 & 3029 & $1.11(1.05-1.17)$ & $1.07(1.01-1.13)$ & $1.05(1.00-1.11)$ \\
\hline$<1$ days/month & 3176 & 581 & $1.02(0.95-1.11)$ & $0.99(0.91-1.07)$ & $0.97(0.90-1.08)$ \\
\hline $1-6$ days/month & 8099 & 1761 & $1.06(0.99-1.13)$ & $1.01(0.95-1.08)$ & $0.99(0.93-1.07)$ \\
\hline 7-14 days/month & 1731 & 425 & $1.28(1.14-1.44)$ & $1.21(1.08-1.37)$ & $1.15(1.04-1.30)$ \\
\hline$\geq 15$ days/month & 984 & 262 & $1.40(1.21-1.62)$ & $1.32(1.13-1.53)$ & $1.26(1.08-1.48)$ \\
\hline$P$ trend & & & $<0.001$ & 0.001 & 0.01 \\
\hline Migraine & 3793 & 864 & $1.23(1.13-1.34)$ & $1.17(1.07-1.28)$ & $1.14(1.04-1.25)$ \\
\hline$<1$ days/month & 599 & 115 & $0.99(0.89-1.10)$ & $0.94(0.84-1.05)$ & $0.92(0.82-1.02)$ \\
\hline 1-6 days/month & 2340 & 526 & $1.19(1.07-1.31)$ & $1.12(1.01-1.25)$ & $1.10(1.00-1.23)$ \\
\hline 7-14 days/month & 625 & 152 & $1.36(1.12-1.64)$ & $1.32(1.09-1.60)$ & $1.24(1.02-1.51)$ \\
\hline$\geq 15$ days/month & 229 & 71 & $1.88(1.42-2.50)$ & $1.72(1.29-2.31)$ & $1.62(1.21-2.17)$ \\
\hline$P$ trend & & & $<0.001$ & $<0.001$ & 0.01 \\
\hline MA & 2139 & 509 & $1.26(1.13-1.40)$ & $1.24(1.11-1.39)$ & $1.15(1.03-1.29)$ \\
\hline$<1$ days/month & 320 & 65 & $1.01(0.90-1.13)$ & $0.95(0.85-1.07)$ & $0.93(0.82-1.04)$ \\
\hline 1-6 days/month & 1290 & 293 & $1.19(1.05-1.35)$ & $1.13(0.99-1.28)$ & $1.09(0.96-1.24)$ \\
\hline 7-14 days/month & 391 & 105 & $1.56(1.23-1.96)$ & $1.51(1.19-1.91)$ & $1.40(1.11-1.77)$ \\
\hline$\geq 15$ days/month & 138 & 46 & $2.15(1.50-3.08)$ & $2.01(1.39-2.90)$ & $1.84(1.27-2.67)$ \\
\hline$P$ trend & & & $<0.001$ & $<0.001$ & 0.002 \\
\hline $\mathrm{MO}$ & 1654 & 355 & $1.17(1.03-1.32)$ & $1.12(0.99-1.27)$ & $1.09(0.96-1.24)$ \\
\hline$<1$ days/month & 279 & 50 & $0.99(0.88-1.11)$ & $0.94(0.84-1.06)$ & $0.92(0.82-1.04)$ \\
\hline $1-6$ days/month & 1050 & 233 & $1.18(1.03-1.35)$ & $1.14(0.99-1.31)$ & $1.13(0.98-1.30)$ \\
\hline 7-14 days/month & 234 & 47 & $1.10(0.79-1.52)$ & $1.08(0.77-1.50)$ & $1.03(0.74-1.44)$ \\
\hline$\geq 15$ days/month & 91 & 25 & $1.58(0.99-2.51)$ & $1.42(0.88-2.28)$ & $1.37(0.85-2.22)$ \\
\hline$P$ trend & & & 0.01 & 0.12 & 0.23 \\
\hline Other headaches & 10,197 & 2165 & $1.08(1.02-1.14)$ & $1.04(0.98-1.11)$ & $1.04(0.97-1.10)$ \\
\hline$<1$ days/month & 2577 & 534 & $1.05(0.96-1.14)$ & $1.01(0.93-1.10)$ & $1.00(0.92-1.09)$ \\
\hline 1-6 days/month & 5759 & 1167 & $1.03(0.96-1.11)$ & $1.00(0.93-1.07)$ & $0.98(0.91-1.05)$ \\
\hline 7-14 days/month & 17,106 & 273 & $1.28(1.11-1.47)$ & $1.20(1.04-1.39)$ & $1.15(1.00-1.33)$ \\
\hline$\geq 15$ days/month & 755 & 191 & $1.29(1.09-1.53)$ & $1.23(1.04-1.46)$ & $1.18(0.99-1.41)$ \\
\hline $\mathrm{P}$ trend & & & $<0.001$ & 0.03 & 0.16 \\
\hline
\end{tabular}

MA Migraine with aura, MO Migraine without aura. Model 1: Adjusted for ag, and sex. Model 2: Adjusted for age, sex and body mass index. Model 3: Adjusted for age, sex, body mass index, smoking, employment status, alcohol use, physical activity and Hospital Anxiety and Depression Scale score

cardiovascular disease has a stronger association to MA than to MO [39].

In this large $(n=38,813)$ population-based study with presumably high statistical power, the association between elevated hs-CRP and headache was evident for those with headache 7-14days/month and headache more than 14 days/month. Correspondingly, elevated hs-CRP was associated with migraine $\geq 7$ days/month, but not migraine $<7$ days/month in the Tromsø study $(n=20,486)$ [29]. This relationship with headache frequency and elevated hs-CRP has not been clearly demonstrated in other studies $[3,4,6-$
$8,14,18-22]$, possibly because of limited statistical power. The results of the present study may be explained by the finding that hs-CRP is related to general pain sensitivity [31]. Alternatively, our findings may be related to potential sterile inflammation in migraine [26] or other types of headaches, most prominent for those with chronic headache. However, whether sterile inflammation is an important pathological feature in migraine and other headaches is still debated.

We evaluated insomnia as a modifying factor on the association between hs-CRP and headache. In contrast 
Table 3 Multi-adjusted ${ }^{a}$ odds ratio (OR) with 95\% confidence interval (Cl) of elevated high sensitivity C-reactive protein (hs-CRP) defined as $>3.0-20.0 \mathrm{mg} / \mathrm{l}$ related to headache types and insomnia status

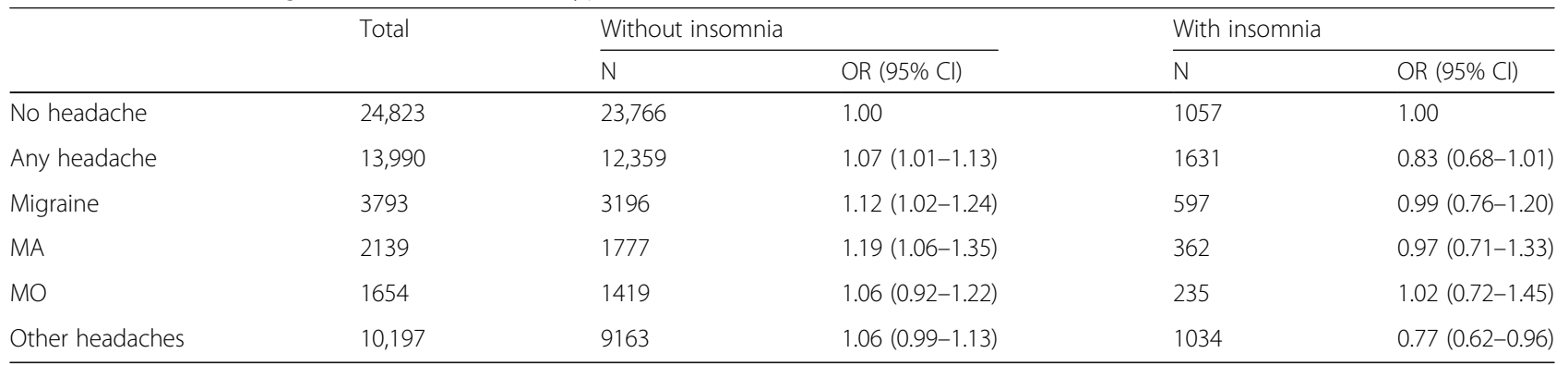

MA Migraine with aura, MO Migraine without aura ${ }^{a}$ Adjusted for age, sex, body mass index, smoking, employment status, alcohol use, physical activity and Hospital Anxiety and Depression Scale score

to the results from the Tromsø 7 Study [26], no association was found between elevated hs-CRP and headache among those with insomnia. The reason for the contrasting finding is unclear. However, it may be a spurious finding in the Tromsø 7 study. An alternative explanation may be that there are differences between participants with insomnia in the Troms $\varnothing 7$ study and in the HUNT3 study. It should be highlighted that the Tromsø Study was performed at almost 70 degree north, with midnight sun and winter darkness periods, whereas the HUNT3 study was performed in middle of Norway at 63-65 degrees north where the difference between summer and winter light is less extreme. The definition of insomnia in the Tromsø 7 study was stricter [29] than the one applied in the HUNT3 study [36], demanding symptoms three or more days per week instead of "several", and with dissatisfaction with sleep quality as mandatory. Despite this, the prevalence of insomnia was higher in Tromsø 7 than in the HUNT3 study $(8.1 \%$ vs. $6.9 \%, p<0.001)[29,36]$. The prevalence reported in the present study is lower than other population-based studies in Norway [40], and we cannot exclude that our findings would have been different using another insomnia questionnaire.

The vast majority (93\%) of the participants did not have insomnia, and in accordance with our main results, we found a relationship between elevated hs-CRP and headache also in this group.

\section{Strengths and limitations of the study}

The present study shares several strengths and limitations with the study from Tromsø [29]. The major strengths of this study are the population-based design and the possibility to perform adjustments for all potential confounding factors previously included in the Tromsø study [29]. The large number of included participants give high statistical power and small confidence intervals.

The most important study limitation is the low participation rate $(41 \%)$. Therefore, generalization of results should be performed with caution. It should also be highlighted that the cross-sectional design does not permit any conclusions about causality. Furthermore, it is a limitation that the diagnoses of headache and insomnia were questionnaire-based, which may have led to misclassification. On the other hand, the agreement between questionnaire-based diagnosis of migraine and interview has previously been found to be acceptable [33]. Insomnia was diagnosed by applying modified DSM-V criteria. DSM-V asks for symptoms three times or more per week [35], whereas the response option "several times per week" was used in the present study [36]. Furthermore, some types of daytime impairment are required in the DSM-V criteria [35]. In this respect it should be noted that our question "felt sleepy during the day?" may not have been optimal way to assess actual sleepiness, as it more probably reflects tiredness and fatigue [36].

\section{Conclusions}

Cross-sectional data based on 38,007 participants showed that elevated hs-CRP was associated with headache $\geq 7$ days/month, most evident for migraine with aura. Elevated hs-CRP was not associated with headache less than 7 days/month or with insomnia.

\section{Abbreviations}

BMI: Body mass index; Cl: Confidence interval; DSM-V: Diagnostic and Statistical Manual of Mental Disorders, 5th ed; Hs-CRP: High sensitivity Creactive protein; HUNT: The Nord-Trøndelag Health Survey; ICHD-2: The International Classification of Headache Disorders 2rd edition; MA: Migraine with aura; MO: Migraine without aura; OR: Odds ration

\section{Acknowledgements}

The Nord-Trøndelag Health Study (The HUNT Study) is a collaboration between HUNT Research Centre (Faculty of Medicine and Health Sciences, Norwegian University of Science and Technology NTNU); Trøndelag County Council, Central Norway Regional Health Authority, and the Norwegian Institute of Public Health.

\section{Authors' contributions}

$\mathrm{KH}$ : Study concept and design, collection of data, analysis and interpretation of data, writing of manuscript. LJS, KBN, ESK and BSW: Interpretation of data, critical revision of manuscript. All authors read and approved the final manuscript. 


\section{Funding}

Not applicable.

\section{Availability of data and materials}

Part of the dataset supporting the conclusions of this article is available on request to the corresponding author. Some of the data are the property of HUNT Research Centre and can only be accessed through direct contact with the research Centre.

\section{Ethics approval and consent to participate}

This study was approved by the Regional Committee for Medical and Health Research Ethics, the Faculty of medicine, mailbox 8905, 7491 Trondheim. The approval number was \#2018/2422/Rek Midt. The participants have given written informed consent.

\section{Consent for publication}

Not applicable.

\section{Competing interests}

The authors declare that they have no competing interests.

\section{Author details}

'Department of Neuromedicine and Movement science, NTNU Norwegian University of Science and Technology, 7491 Trondheim, Norway. ${ }^{2}$ Norwegian Advisory Unit on Headache, St. Olavs Hospital, Trondheim, Norway. ${ }^{3}$ Clinical Trial Unit, St. Olavs Hospital, Trondheim, Norway. ${ }^{4}$ Department of Neurology, Oslo University Hospital, Oslo, Norway. ${ }^{5}$ Department of General Practice, HELSAM, University of Oslo, Oslo, Norway. ${ }^{6}$ Department of Neurology, Akershus University Hospital, Lørenskog, Norway. ${ }^{7}$ Department of Neurology and FORMI, Oslo University Hospital, Oslo, Norway. Institute of Clinical Medicine, University of Oslo, Oslo, Norway.

\section{Received: 12 June 2019 Accepted: 11 September 2019} Published online: 26 September 2019

\section{References}

1. Welch KM, Brandes AW, Salerno L, Brandes JL. C-reactive protein may be increased in migraine patients who present with complex clinical features. Headache. 2006:46:197-9.

2. Silva FA, Rueda-Clausen CF, Silva SY, Zarruk JG, Guzmán JC, Morillo CA, Vesga B, Pradilla G, Flórez M, López-Jaramillo P. Endothelial function in patients with migraine during the interictal period. Headache. 2007;47:45-51.

3. Vanmolkot FH, de Hoon JN. Increased C-reactive protein in young adult patients with migraine. Cephalalgia. 2007;27:843-6.

4. Kurth T, Ridker PM, Buring JE. Migraine and biomarkers of cardiovascular disease in women. Cephalalgia. 2008;28:49-56

5. Guldiken B, Guldiken S, Demir M, Turgut N, Kabayel L, Ozkan H, Ozcelik E, Tugrul A. Insulin resistance and high sensitivity C-reactive protein in migraine. Can J Neurol Sci. 2008;35:448-51.

6. Gudmundsson LS, Aspelund T, Scher Al, Thorgeirsson G, Johannsson M, Launer LJ, Gudnason V. C-reactive protein in migraine sufferers similar to that of non-migraineurs: the Reykjavik study. Cephalalgia. 2009;29:1301-10.

7. Tietjen GE, Herial NA, White L, Utley C, Kosmyna JM, Khuder SA. Migraine and biomarkers of endothelial activation in young women. Stroke. 2009;40: 2977-82.

8. Hamed SA, Hamed EA, Ezz Eldin AM, Mahmoud NM. Vascular risk factors, endothelial function, and carotid thickness in patients with migraine: relationship to atherosclerosis. J Stroke Cerebrovasc Dis. 2010;19:92-103.

9. Nelson KB, Richardson AK, He J, Lateef TM, Khoromi S, Merikangas KR. Headache and biomarkers predictive of vascular disease in a representative sample of US children. Arch Pediatr Adolesc Med. 2010;164:358-62.

10. Guldiken S, Guldiken B, Demir M, Kabayel L, Ozkan H, Turgut N, Hunkar R, Kat S. Soluble CD40 ligand and prolactin levels in migraine patients during interictal period. J Headache Pain. 2011;12:355-60.

11. Yilmaz N, Aydin O, Yegin A, Tiltak A, Eren E. Increased levels of total oxidant status and decreased activity of arylesterase in migraineurs. Clin Biochem. 2011:44:832-7

12. Theodoropoulos DS, Katzenberger DR, Jones WM, Morris DL, Her C, Cullen NA, Morrisa DL. Allergen-specific sublingual immunotherapy in the treatment of migraines: a prospective study. Eur Rev Med Pharmacol Sci. 2011;15:1117-21.
13. Tietjen GE, Khubchandani J, Herial NA, Shah K. Adverse childhood experiences are associated with migraine and vascular biomarkers. Headache. 2012;52:920-9.

14. Güzel I, Taşdemir N, Celik Y. Evaluation of serum transforming growth factor $\beta 1$ and C-reactive protein levels in migraine patients. Neurol Neurochir Pol. 2013:47:357-62

15. Rockett FC, Perla Ada S, Perry ID, Chaves ML. Cardiovascular disease risk in women with migraine. J Headache Pain. 2013;14:75.

16. Fava A, Pirritano D, Consoli D, Plastino M, Casalinuovo F, Cristofaro S, Colica C, Ermio C, De Bartolo M, Opipari C, Lanzo R, Consoli A, Bosco D. Chronic migraine in women is associated with insulin resistance: a cross-sectional study. Eur J Neurol. 2014;21:267-72.

17. Mottaghi T, Askari G, Khorvash F, Maracy MR. Effect of vitamin D supplementation on symptoms and C-reactive protein in migraine patients. J Res Med Sci. 2015;20:477-82

18. Tanik N, Celikbilek A, Metin A, Gocmen AY, Inan LE. Retinol-binding protein4 and hs-CRP levels in patients with migraine. Neurol Sci. 2015;36:1823-7.

19. Avci AY, Lakadamyali H, Arikan S, Benli US, Kilinc M. High sensitivity Creactive protein and cerebral white matter hyperintensities on magnetic resonance imaging in migraine patients. J Headache Pain. 2015;16:9.

20. Peng YF, Wei Y, Qin YH, Wei YS, Teng YJ. A relationship between absolute monocyte count and C-reactive protein in patients with migraine undergoing no pharmacological therapy. Clin Chem Lab Med. 2016;54:e249-51.

21. Peng YF, Xie LQ, Xiang Y, Xu GD. Serum bilirubin and their association with C-reactive protein in patients with migraine. J Clin Lab Anal. 2016;30:982-5.

22. Gürger M, Atescelik M, Yilmaz M, Yildiz M, Kalayci H, Kobat MA, Demir CF. Can we define migraine patients with blood high-sensitivity C-reactive protein and galectin-3 levels in the emergency department? Arch Med Sci. 2018;14:307-12.

23. Domínguez C, Vieites-Prado A, Pérez-Mato M, Sobrino T, Rodríguez-Osorio X, López A, Campos F, Martínez F, Castillo J, Leira R. Role of adipocytokines in the pathophysiology of migraine: a cross-sectional study. Cephalalgia. 2018;38:904-11.

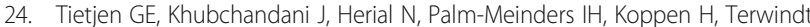
GM, van Buchem MA, Launer LJ, Ferrari MD, Kruit MC. Migraine and vascular disease biomarkers: a population-based case-control study. Cephalalgia. 2018;38:511-8.

25. Abdolahi M, Sarraf $P$, Javanbakht MH, Honarvar NM, Hatami M, Soveyd N, Tafakhori A, Sedighiyan M, Djalali M, Jafarieh A, Masoudian Y, Djalali M. A novel combination of $\omega-3$ fatty acids and nano-curcumin modulates interleukin-6 gene expression and high sensitivity C-reactive protein serum levels in patients with migraine: a randomized clinical trial study. CNS Neurol Disord Drug Targets. 2018;17:430-8.

26. Lippi G, Mattiuzzi C, Cervellin G. C-reactive protein and migraine. Facts or speculations? Clin Chem Lab Med. 2014;52:1265-72.

27. Uhlig BL, Engstrøm M, Ødegård SS, Hagen K, Sand T. Headache and insomnia in population-based studies. Cephalalgia. 2014;34:745-51.

28. Ferrie JE, Kivimäki M, Akbaraly TN, Singh-Manoux A, Miller MA, Gimeno D, Kumari M, Davey Smith G, Shipley MJ. Associations between change in sleep duration and inflammation: findings on C-reactive protein and interleukin 6 in the Whitehall II study. Am J Epidemiol. 2013;178:956-61.

29. Hagen K, Hopstock L, Eggen A, Mathiesen E, Nilsen KB. Does insomnia modify the association between c-reactive protein and migraine? The Tromsø study 2015-2016. Cephalalgia. 2019; [Epub ahead of print].

30. Krokstad S, Langhammer A, Hveem K, et al. Cohort profile: the HUNT study, Norway. Int J Epidemiol. 2013;42:968-77.

31. Schistad El, Stubhaug A, Furberg AS, Engdahl BL, Nielsen CS. C-reactive protein and cold-pressor tolerance in the general population: the Troms $\varnothing$ study. Pain. 2017;158:1280-8.

32. Kushner I, Rzewnicki D, Samols D. What does minor elevation of C-reactive protein signify? Am J Med. 2006;119:17-28.

33. Hagen $\mathrm{K}$, Zwart JA, Aamodt AH, et al. The validity of questionnaire-based diagnoses: the third Nord-Trøndelag health study 2006-2008. J Headache Pain. 2010;11:67-73.

34. Headache Classificiation Committee of the International Headache Society (IHS). The international classification of headache disorders 2 nd edition. Cephalalgia. 2004;24(Suppl 1):2-150.

35. Association AP. Diagnostic and statistical manual of mental disorders: DSMV. Washington (DC): American Psychiatric Publishing; 2013.

36. Uhlig BL, Sand T, Ødegård SS, Hagen K. Prevalence and associated factors of DSM-V insomnia in Norway. The HUNT 3 study. Sleep Med. 2014;15:708-13. 
37. Engstrøm M, Ødegård SS, Sand T, Stovner L, Zwart JA, Hagen K. The reliability of a sleep questionnaire in a large population-based study: the third Nord-Trøndelag health study. Open Sleep J. 2011;4:14-9.

38. Wang TJ, Larson MG, Levy D, Benjamin EJ, Kupka MJ, Manning WJ, Clouse ME, D'Agostino RB, Wilson PW, O'Donnell CJ. C-reactive protein is associated with subclinical epicardial coronary calcification in men and women: the Framingham heart study. Circulation. 2002;106:1189-91.

39. Sacco S, Kurth T. Migraine and the risk for stroke and cardiovascular disease. Curr Cardiol Rep. 2014;16:524.

40. Pallesen S, Sivertsen B, Nordhus IH, Bjorvatn B. A 10-year trend of insomnia prevalence in the adult Norwegian population. Sleep Med. 2014:15:173-9.

\section{Publisher's Note}

Springer Nature remains neutral with regard to jurisdictional claims in published maps and institutional affiliations.

Ready to submit your research? Choose BMC and benefit from:

- fast, convenient online submission

- thorough peer review by experienced researchers in your field

- rapid publication on acceptance

- support for research data, including large and complex data types

- gold Open Access which fosters wider collaboration and increased citations

- maximum visibility for your research: over $100 \mathrm{M}$ website views per year

At $B M C$, research is always in progress.

Learn more biomedcentral.com/submissions 